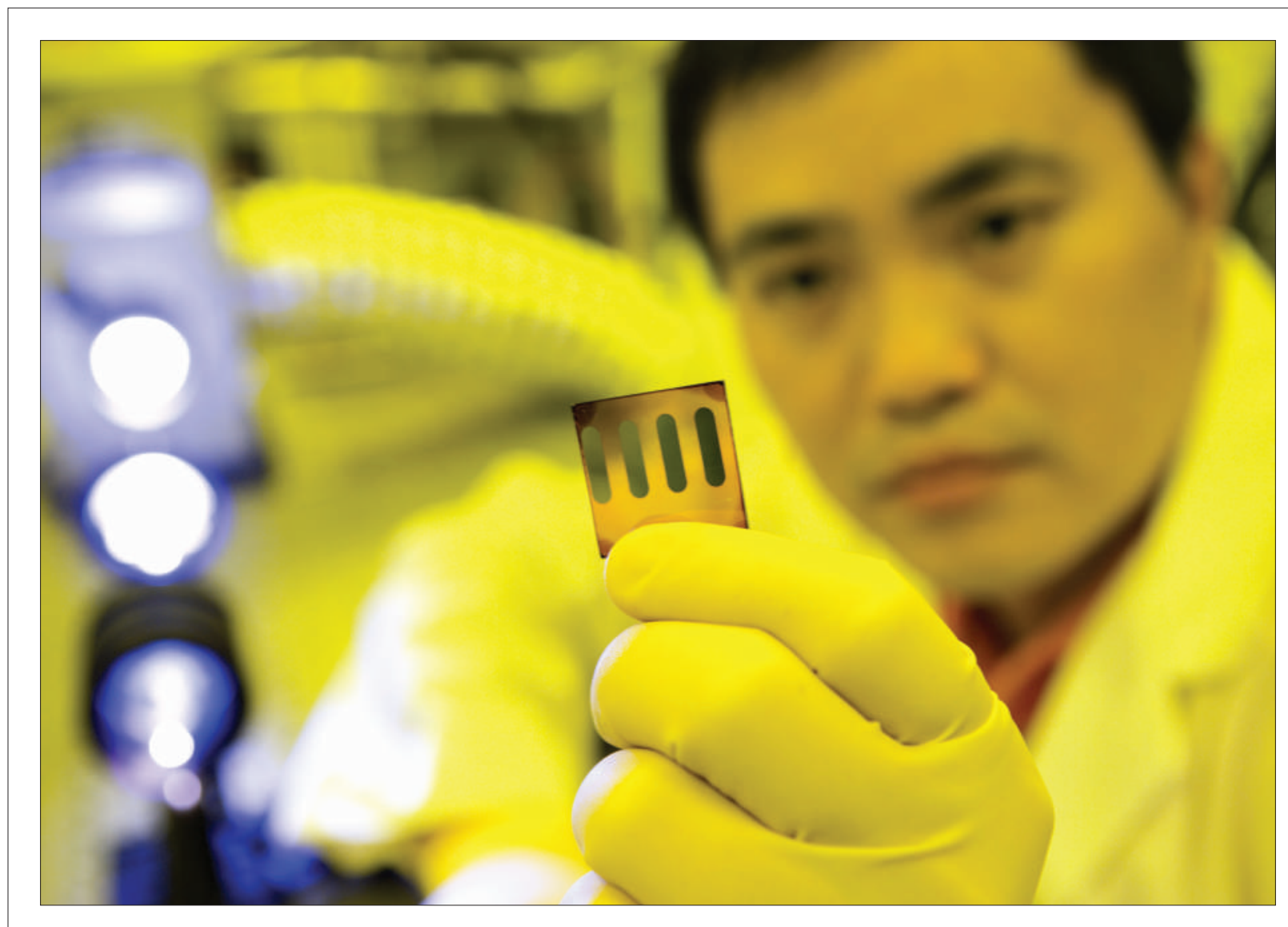

Singapore Journal of

Scientific Research

ISSN: 2010-006x 


\title{
Research Article \\ Effect of Plants Powdered Extracts against Lesser Grain Borer (Rhyzopertha dominica) Infestation of Stored Wheat
}

\author{
H.E. Negbenebor and S. Nura \\ ${ }^{1}$ Department of Computing and Applied Sciences, Baze University, Abuja, Nigeria \\ ${ }^{2}$ Department of Biology, Ahmadu Bello University, Zaria, Nigeria
}

\begin{abstract}
Background and Objective: Insect pests such as Rhyzopertha dominica have become a euphemism to wheat farmers and traders in Africa in general and Nigeria in particular due to the heavy loss they impart onto the stored wheat grains. This study was carried out to investigate the toxicity of powdered extracts obtained from three different species of plants: Tephrosia vogelii, Hyptis suaveolens and Alstonia boonei in protecting stored wheat grains from (Rhyzopertha dominica) infestation. Materials and Methods: Five different powdered doses were made from the leaves of the test plants with $0.0 \mathrm{~g} / 20 \mathrm{~g}$ as the control (ethanol). The powdered doses were applied onto wheat grains and the test insect introduced. The experiment was laid in a Completely Randomized Design (CRD) with three replications. Data were collected from adult mortality, a number of eggs laid, larval development and grain damage. The data were subjected to analysis of variance at a 5\% probability level with Duncan's Multiple Range Test (DMRT) used to separate the significant means. Results: Significant difference $(p \leq 0.05)$ was found in the degree of toxicity imparted by various doses of the extracts on to the test insect. The high rate of mortality, reduced number of laid eggs and percentage of the emerged insects from the laid eggs were found among the treatments with respect to the control. The toxicity of the extracts increased with an increase in dose. Conclusion: It was concluded that $8.0 / 20 \mathrm{~g}$ of the powdered extracts were more toxic to the test insect. It was recommended that $8.0 \mathrm{~g} / 20 \mathrm{~g}$ of $T$. vogelii be used in the control of $R$. dominica.
\end{abstract}

Key words: Dose, Duncan's multiple range test infestation, powdered extracts, Rhyzopertha dominica, wheat, mortality

Citation: Negbenebor H.E. and S. Nura, 2020. Effect of plants powdered extracts against lesser grain borer (Rhyzopertha dominica) infestation of stored wheat. Singapore J. Sci. Res., 10: 451-457.

Corresponding Author: S. Nura, Department of Biology, Ahmadu Bello University, Zaria, Nigeria

Copyright: (c) 2020 H.E. Negbenebor and S. Nura. This is an open access article distributed under the terms of the creative commons attribution License, which permits unrestricted use, distribution and reproduction in any medium, provided the original author and source are credited.

Competing Interest: The authors have declared that no competing interest exists.

Data Availability: All relevant data are within the paper and its supporting information files. 


\section{INTRODUCTION}

Wheat (Triticum aestivum) is a monocotyledonous plant of the family Poaceae ${ }^{1}$. It is the world's most important staple food for humans in relation to production and consumption? ${ }^{2}$ Wheat is grown on more land area than any other commercial crop. World trade in wheat is higher than all other crops combined $^{3}$. It is the most proteinous grain consumed in developing countries to combat malnutrition in young children, especially in Nigeria ${ }^{2}$. However, despite its relative importance in curbing malnutrition and hunger in Nigeria and the world at large, it is attacked by various insect pests between harvest and storage. Stored product pests represent the most important group of pests 4 . The most economically important insect pest of stored wheat is the lesser grain borer Rhizopertha dominica ${ }^{25,6}$. The $R$. dominica is a field-to-store pest and this may cause economic damage in the store ${ }^{5}$.

Rhyzopertha dominica (Fabricius, 1792) (Coleoptera: Bostrichidae) is one of the most injurious pests of stored grains both in larval and adult stage ${ }^{7,8}$. The adults are sturdy fliers, which fly from warehouse to warehouse, causing severe infestation and convert the stored grains to mere frass thereby imparting significant economic losses in terms of grain mass and nutrient depletion and pose a public health risk from contamination by allergens such as uric acid ${ }^{9-11}$. The major strategy employed in its management and control in Nigeria is the application of synthetic chemicals that possessed several problems. These include conferring resistance to the insect pest, pest resurgence and lethal effects on non-target organisms in addition to direct toxicity to users and impart health hazards coupled with environmental contamination and expensive ${ }^{12-18}$. The use of botanical insecticides is seen as an alternative method for insect pests control and management ${ }^{19-23}$. Unlike synthetic insecticides, which mostly kill insects, plant ingredients are known to suppress the feeding and breeding behavior of insects in many ways in addition to direct mortality ${ }^{24}$. The use of plant parts with insecticidal properties has been reported from all over the world as they are convenient, less expensive, highly effective and safer for humans and environment ${ }^{25-31}$. This study therefore aimed at investigating the toxicity of three plants leaves powdered extracts against $R$. dominica infestation of stored wheat grains.

\section{MATERIALS AND METHODS}

Study area: The research was conducted at the Entomology laboratory of Nigeria Stored Products Research Institute
(NSPRI) Lagos, Nigeria (Latitude $6^{\circ}, 30^{\prime} \mathrm{N}$, Longitude $3^{\circ}, 23^{\prime} \mathrm{E}$ ). The research was conducted for a period of 24 months.

Test plants: Fresh leaves of Hyptis suaveolens (Lamiaceae), Alstonia boonei (Apocynaceae) and Tephrosia vogelii (Fabaceae) were procured from vendors at Oyingbo market in Lagos and identified in the Herbarium of the Department of Botany, University of Lagos, Nigeria.

Source of insects: The larvae and adults of $R$. dominica were derived from a laboratory mass-rearing facility. Insects were supplied with fresh wheat grains and were reared in wood cages according to the technique described by Dabire et $\mathrm{a} / .^{32}$. Toxicity tests were carried out on $1 \mathrm{st}$, 3 rd and 5 th instars larvae and adults of $R$. dominica:

Toxicity Factor $(\mathrm{TF})=\frac{48 \mathrm{hrs} \mathrm{LC}_{50} \text { value of the least toxic compound }}{48 \mathrm{hrs} \mathrm{LC}_{50} \text { value of the more toxic compound }}$

Preparation of plants powdered extracts: The fresh leaves of the three test plants: Hyptis suaveolens, Alstonia booneiand Tephrosia vogelii were air-dried at room temperature, pounded to a fine powder by pestle and mortar according to the protocols described by Dabire et al. ${ }^{33}$. The powders were further sieved to pass through $1 \mathrm{~mm}^{2}$ meshes as described by lleke and Bulus ${ }^{16}$. The powders were packed in plastic containers with tight lids and kept in the dark according to the method described by Udo ${ }^{14}$.

Disinfestation of test wheat grains: Wheat grains were obtained from the Bariga market, Lagos. They were identified at the International Institute of Tropical Agriculture (IITA), Ibadan. All damaged seeds and debris were sorted out from the grains after which disinfestations were carried out in an oven at $50^{\circ} \mathrm{C}$ for six hours to kill all life stages of insects within the grains. The grains were then left respectively for $24 \mathrm{hrs}$ to stabilize at ambient conditions.

Culture of test insects: $R$. dominica(Fab.) were maintained on disinfested wheat grains. Fifty unsexed 7-14 day old adults of R. dominica were introduced into $500 \mathrm{~g}$ of disinfested wheat grains in $1 \mathrm{~L}$ Kilner jars respectively in three replicates in the laboratory. All adult insects were left for seven days to allow for oviposition, after which they were removed. They were then left undisturbed until adults were observed to emerge. At each peak of emergence, the adults were removed and used to set up new cultures. Series of fresh cultures were made from these to ensure regular supply of adult insects of known ages for use in subsequent experiments. 
Experimental design: Fifty grams of disinfested wheat grains were measured into each of the six plastic containers. 0.5, 1.0, 2.0, 4.0 and $8.0 \mathrm{~g} / 20 \mathrm{~g}$ of Hyptis suaveolens, Alstonia boonei and Tephrosia vogelii were applied on the grains and manually agitated. The controls were treated with ethanol. Thirty unsexed insects were released into each plastic container as well as that of the control. The experiment is arranged in a Completely Randomized Design with three replications. The containers were kept in the laboratory. Monthly readings were taken for six months in which $20 \mathrm{~g}$ of the treated and untreated wheat were taken from each container and assessed for insect damage according to Odeyemi and Ashamo ${ }^{34}$.

Insect damage in grains: Monthly insect damage in each treatment and control was determined from $100 \mathrm{~g}$ batches of grains in each jute bag as described by another study ${ }^{34}$.

$$
\text { Percentage weight loss }=\frac{\left(\mathrm{W}_{\mathrm{u}} \times \mathrm{N}_{\mathrm{d}}\right)-\left(\mathrm{W}_{\mathrm{d}} \times \mathrm{N}_{\mathrm{u}}\right)}{\mathrm{W}_{\mathrm{u}}\left(\mathrm{N}_{\mathrm{d}}+\mathrm{N}_{\mathrm{u}}\right)} \times 100
$$

Where:

$\mathrm{W}_{\mathrm{u}}$ : Weight of undamaged grains

$\mathrm{N}_{\mathrm{u}}$ : Number of undamaged grains

$W_{d}$ : Weight of damaged grains

$\mathrm{N}_{\mathrm{d}}$ : Number of damaged grains

Data analysis: The data obtained were analyzed using Analysis of Variance (ANOVA) using SPSS (11.0 versions) with Duncan's Multiple Range Test used to compare the significant means.

\section{RESULTS}

The result obtained for the toxicity of the powdered extracts on $R$. dominica is presented in Table 1 . The result showed that powdered extracts from Tephrosia vogelii are the most toxic to $R$. dominica with $\mathrm{LC}_{50}$ value of 9.58 at $48 \mathrm{hrs}$ of exposure. While Alstonia booneipowdered extracts are the least toxic with $\mathrm{LC}_{50}$ of 23.47 at $48 \mathrm{hrs}$ of exposure.

The result for the percentage mortality of $R$. dominica due to exposure to different powdered extracts from the three test plants is shown in Table 2. The result indicated that, $8.0 \mathrm{~g} / 20 \mathrm{~g}$ of the powdered extracts obtained from T. vogelii, $H$. suaveolens and $A$. boonei induced highest percentage mortality of $77.3,64.7$ and $58.15 \%$, respectively. The percentage of mortality increases with an increase in concentration.

The result for the percentage inhibition of oviposition and progenies development induced by various concentrations of the test plants is presented in Table 3. The result showed that 18 eggs were laid under $8.0 \mathrm{mg} \mathrm{L}^{-1}$ of Tephrosia vogelii powdered extracts out of which only $28.55 \%$ emerged as adults. Similarly, the least number of eggs laid and the percentage adult emergence were found under $8.0 \mathrm{~g} / 20 \mathrm{~g}$ of the remaining test plant extracts. The number of eggs laid and the percentage of adult emergence decrease with an increase in concentrations.

However, the result for the average mean percentage of damage induced by $R$. dominica on the treated wheat grains is shown in Table 4. The result revealed that the mean percentage damage of the test insect on wheat grains treated with various doses of $T$. vogelii extracts for a period of six months reduced from $4.17 \%$ to as low as $0.35 \%$ with an increase in dose. These values are significantly lower than that of the control (9.12\%). More so, the grains treated with $H$. suaveolens extracts reduced the infestation rate from $5.06 \%$ to as low as $1.02 \%$ with an increase in dose. A similar result was found in terms of the grains treated with $A$. boonei extracts (the infestation rate reduced from 5.49 to $1.29 \%$ ) with an increase in dose. Complete protection of the grains for three months was found in $8.0 \mathrm{~g} / 20 \mathrm{~g}$ dose obtained from T. vogelii while the remaining extracts give full protection for two months.

Table 1: Relative toxicity of various test plant Powdered extracts on $R$. dominica

\begin{tabular}{|c|c|c|c|c|c|c|}
\hline Ethanolic extracts & $24 \mathrm{hrs} \mathrm{LC}{ }_{50}(\mathrm{~g} / 20 \mathrm{~g})$ & $95 \% \mathrm{CL}$ & TF & $48 \mathrm{hrs}^{\mathrm{L} C_{50}}$ & $95 \% C L$ & TF \\
\hline Tephrosia vogelii & 12.74 & - & 1.03 & 9.58 & - & 1.05 \\
\hline Hyptis suaveolens & 16.56 & - & 1.34 & 19.48 & - & 2.14 \\
\hline Alstonia boonei & 19.77 & $13.76-45.51$ & 1.63 & 23.47 & - & 2.58 \\
\hline
\end{tabular}

Table 2: Mortality of $R$. dominica adults due to exposure treated grains with Powdered extracts of test plants

\begin{tabular}{|c|c|c|c|c|c|c|}
\hline Ethanolic extract & $0.0 \mathrm{~g} / 20 \mathrm{~g}$ & $0.5 \mathrm{~g} / 20 \mathrm{~g}$ & $1.0 \mathrm{~g} / 20 \mathrm{~g}$ & $2.0 \mathrm{~g} / 20 \mathrm{~g}$ & $4.0 \mathrm{~g} / 20 \mathrm{~g}$ & $8.0 \mathrm{~g} / 20 \mathrm{~g}$ \\
\hline Tephrosia vogelii & $0.00^{\mathrm{a}^{* 1}}$ & $38.0^{a}$ & $51.5^{\mathrm{a}}$ & $62.3^{\mathrm{a}}$ & $68.9^{a}$ & $77.3^{\mathrm{a}}$ \\
\hline Hyptis suaveolens & $0.00^{\mathrm{a}}$ & $26.5^{b}$ & $37.0^{b}$ & $50.2^{b}$ & $57.7^{b}$ & $64.7^{b}$ \\
\hline Alstonia boonei & $0.00^{\mathrm{a}}$ & $25.0^{\mathrm{b}}$ & $31.5^{c}$ & $46.9^{c}$ & $51.2^{c}$ & $58.1^{c}$ \\
\hline
\end{tabular}

N.B: *1 Mean values bearing the same superscript(s) down a column are not significantly different $(p=0.05)$ 
Singapore J. Sci. Res., 10 (4): 451-457, 2020

Table 3: Oviposition and progeny development of $R$. dominica on wheat grains

\begin{tabular}{lcccc}
\hline Plant extract & Concentration $(\mathrm{g} / 20 \mathrm{~g})$ & Mean number of eggs laid & Mean adult emergence & Mean percent adult emergence (\%) \\
\hline Tephrosia vogelii & 0.00 & $89.73^{\mathrm{a}}$ & $83.79^{\mathrm{a}}$ & 93.38 \\
& 1.0 & $52.45^{\mathrm{b}}$ & $26.08^{\mathrm{b}}$ & 49.72 \\
& 2.0 & $40.32^{\mathrm{c}}$ & $18.90^{\mathrm{c}}$ & 46.88 \\
& 4.0 & $35.11^{\mathrm{d}}$ & $13.05^{\mathrm{d}}$ & 37.17 \\
Hyptis suaveolens & 8.0 & $18.25^{\mathrm{e}}$ & $5.210^{\mathrm{e}}$ & 28.55 \\
& 0.00 & $87.98^{\mathrm{a}}$ & $82.25^{\mathrm{a}}$ & 93.49 \\
& 1.0 & $59.02^{\mathrm{b}}$ & $35.20^{\mathrm{b}}$ & 59.64 \\
& 2.0 & $48.97^{\mathrm{c}}$ & $28.30^{\mathrm{c}}$ & 57.79 \\
Alstonia boonei & 4.0 & $40.37^{\mathrm{d}}$ & $21.20^{\mathrm{d}}$ & 52.51 \\
& 8.0 & $25.13^{\mathrm{e}}$ & $10.70^{\mathrm{e}}$ & 42.58 \\
& 0.00 & $87.25^{\mathrm{a}}$ & $81.06^{\mathrm{a}}$ & 92.91 \\
& 1.0 & $60.28^{\mathrm{b}}$ & $43.12^{\mathrm{b}}$ & 71.53 \\
& $55.14^{\mathrm{c}}$ & $35.20^{\mathrm{c}}$ & 63.84 \\
\end{tabular}

${ }^{* 1}$ Means bearing the same superscripts down a column are not significantly different $(p=0.05)$

Table 4: Percentage mean damage by $R$. dominica on treated wheat grains

\begin{tabular}{|c|c|c|c|c|c|c|}
\hline Extract & $0.0 \mathrm{~g} / 20 \mathrm{~g}$ & $0.5 \mathrm{~g} / 20 \mathrm{~g}$ & $1.0 \mathrm{~g} / 20 \mathrm{~g}$ & $2.0 \mathrm{~g} / 20 \mathrm{~g}$ & $4.0 \mathrm{~g} / 20 \mathrm{~g}$ & $8.0 \mathrm{~g} / 20 \mathrm{~g}$ \\
\hline \multicolumn{7}{|l|}{ T. vogelii } \\
\hline 1st Month & 1.69 & 0.00 & 0.00 & 0.00 & 0.00 & 0.00 \\
\hline 2nd Month & 4.54 & 0.00 & 0.00 & 0.00 & 0.00 & 0.00 \\
\hline 3rd Month & 6.23 & 2.15 & 0.76 & 0.27 & 0.04 & 0.00 \\
\hline 4th Month & 10.16 & 3.68 & 1.44 & 0.98 & 0.26 & 0.08 \\
\hline 5th Month & 13.25 & 6.92 & 3.91 & 2.83 & 1.89 & 0.95 \\
\hline 6th Month & 18.84 & 12.27 & 9.85 & 5.94 & 3.64 & 1.04 \\
\hline Mean & 9.12 & 4.17 & 2.66 & 1.67 & 0.97 & 0.35 \\
\hline \multicolumn{7}{|c|}{ H. suaveolens } \\
\hline 1st Month & 1.71 & 0.00 & 0.00 & 0.00 & 0.00 & 0.00 \\
\hline 2nd Month & 4.21 & 0.00 & 0.00 & 0.00 & 0.00 & 0.00 \\
\hline 3rd Month & 6.40 & 2.79 & 1.24 & 1.10 & 0.94 & 0.56 \\
\hline 4th Month & 9.98 & 5.28 & 3.56 & 1.78 & 1.05 & 0.82 \\
\hline 5th Month & 13.82 & 8.04 & 6.93 & 3.51 & 2.52 & 1.96 \\
\hline 6th Month & 19.65 & 14.26 & 11.07 & 7.95 & 5.33 & 2.79 \\
\hline Mean & 9.29 & 5.06 & 3.80 & 2.39 & 1.64 & 1.02 \\
\hline \multicolumn{7}{|l|}{ A. boonei } \\
\hline 1st Month & 1.68 & 0.00 & 0.00 & 0.00 & 0.00 & 0.00 \\
\hline 2nd Month & 4.61 & 0.00 & 0.00 & 0.00 & 0.00 & 0.00 \\
\hline 3rd Month & 6.29 & 2.68 & 2.38 & 1.37 & 1.13 & 0.87 \\
\hline 4th Month & 10.20 & 6.03 & 5.01 & 2.86 & 2.41 & 1.03 \\
\hline 5th Month & 12.99 & 8.59 & 6.96 & 4.92 & 3.11 & 2.69 \\
\hline 6th Month & 18.74 & 15.68 & 13.31 & 9.05 & 7.89 & 3.14 \\
\hline Mean & 9.09 & 5.49 & 4.61 & 3.03 & 2.42 & 1.29 \\
\hline
\end{tabular}

\section{DISCUSSION}

In view of the excellent possibilities to use plant extracts against $R$. dominica infestation of stored wheat grains, the three plant powdered extracts were found to be essential as they conferred certain degrees of toxicity to the test insect. T. vogelii extracts prevent more than $50 \%$ of the eggs laid to emerge. This finding is in agreement with that of Ogendo et al 35 who reported toxicity of Tephrosia vogeliion S. oryzae inducing more than $50 \%$ insect mortality. More so, Babarinde et al..$^{36}$ and Odewole ${ }^{37}$ individually reported that extracts of $T$. vogelii exhibited strong insecticidal activity against several insect pests of crops. Similarly, Koona and Dorn ${ }^{38}$ reported powdered hexane extracts of dried leaves of T. vogeliieffective protectants of stored legume seeds against bruchids infestation and reduced the damage caused by Callosobrunchusmaculatus, C. chinensisand Acanthoscelides obtectus on the treated seeds by $7.1 \%$ compared with $99.8 \%$ recorded on grains in the control experiment. These findings, therefore, proved the assertion made by Belmain et al. ${ }^{39}$ that, plant extracts have potentials against insect pests infestation of stored products. Similarly, lleke and Bulus ${ }^{16}$ reported toxicity of powders and extracts of Azadirachta indica and Piper guineense seeds to $R$. dominica. Thus, botanicals extracts 
have been reported by Amuji et al. ${ }^{40}$ to exhibit an appreciable magnitude of toxicity to insects inducing mortality.

The toxicity of the three plant extracts revealed by this study has therefore confirmed the previous findings of Oumarou et al/41 who reported the bioefficacy of Hyptis suaveolens extracts on Anopheles gambiae, lleke and Emmanue ${ }^{42}$ reported high bioefficacy of $A$ Astonia booneileaf extract against cowpea beetle (Callosobrochus maculatus) infestation of stored cowpea seeds. Similarly, Emeasor and Ndumele $^{43}$ reported the insecticidal potency of aqueous extract of Tephrosia vogelii in the control of insect pests of cucumber (Cucumis sativus L.). The toxicity of these plants powdered extracts can probably be attributed to the various chemical constituents present in the extracts as stressed by Mbailao et $a / .^{44}$ and Ileke and Oni ${ }^{13}$.

The effect of the three test plants extracts in suppressing progeny development and oviposition of $R$. dominica can be attributed to the toxicity and lethality conferred by the extracts on the oviposition thereby interfering with the physiological process of developing eggs. This finding conforms with that of Osawe et $a / .{ }^{45}$ who reported extracts of A. boonei leaves adversely affected the survival and growth of Sesamia calamistis. Similarly, Meena et a/.6 ${ }^{46}$ reported suppression of progeny development of rice moth (Corcyra cephalonica) by plant extracts. The growth inhibition may result from toxicity or feeding deterrent properties of the plant as reported by several authors such as Akhtar and Isman ${ }^{47}$, Hikal et al. ${ }^{48}$ and Suleiman et al.$^{49}$ who individually reported insecticidal efficacy of some plant extracts in suppressing progeny development of stored insect pests.

The protection capacity of the three plants powdered extracts is in agreement with the work of Abdullahi et $a / .^{50}$ who reported the protection ability of lime in reducing the grain damage caused by storage pests. Negbenebor and Nura ${ }^{51}$ reported that ethanolic extracts obtained from the leaves of Hyptis suaveolens, Alstonia boonei and Tephrosia vogelli protected stored cowpea seed from damage by cowpea weevil when stored in airtight plastic containers without affecting the seed viability. A similar finding is reported by lliyasu and Gabriella ${ }^{52}$. The toxicity of the three plant extracts on the test organism is an indication of the relative importance of the powdered extracts in preventing the wheat grains from damage by $R$. dominica infestation. This may increase the longevity of the seeds and their market qualities without disrupting the nutritional qualities. This finding, therefore, adds to the existing data on the efficacy of plant extracts as biopesticides of stored food. Thus, the findings from this study implied that powdered extracts obtained from leaves of $H$. suaveolens, A. boonei and T. vogelii possessed potential insecticidal properties against lesser grain borer and as such control the insect's infestation of stored wheat. However, higher doses of the powdered extracts were recommended for use against lesser grain borer.

\section{CONCLUSION}

It was concluded that powdered extracts from the leaves of $H$. suaveolens, A. boonei and T. vogelii have high toxicity to $R$. dominica thereby protecting wheat grains from its infestation to as long as three to six months. The effect of the extracts is dose-dependent, increases with an increase in dose. Thus, 8.0/20 g of the powdered extracts of $T$. vogelii is highly recommended for biological control of $R$. dominica in stored wheat grains.

\section{SIGNIFICANCE STATEMENT}

This study discovered that powdered extracts obtained from the three test plants are effective in protecting wheat grains from Rhyzopertha dominica infestation. As such, the extracts can be beneficial in the biological control of the pest using natural insecticides. It adds to the existing list of plants with insecticidal potency. This study will also help the researchers to uncover the critical areas of using bio-pesticides that many researchers were not able to explore. Thus a new theory on the effects of natural botanical pesticides in the biological control of insect pests of stored products may be arrived at.

\section{REFERENCES}

1. Mehmood, Z., M. Ashiq, I.R. Noorka, A. Ali, S. Tabasum and M.S. Iqbal, 2014. Chemical control of monocot weeds in wheat (Triticum aestivum L.). Am. J. Plant Sci., 05: 1272-1276.

2. Ileke, K.D., 2013. Insecticidal activity of four medicinal plant powders and extracts against Angoumois grain moth, Sitotroga cerealella(Olivier) [Lepidoptera:Gelechidae]. Egypt. J. Biol., 15: 21-27.

3. Enghiad, A., D. Ufer, A.M. Countryman and D.D. Thilmany, 2017. An overview of global wheat market fundamentals in an era of climate concerns. Int. J. Agron., Vol. 2017. 10.1155/2017/3931897

4. Abd El-Aziz, S.E., 2011. Control strategies of stored product pests. J. Entomol., 8: 101-122.

5. Adedire, C.O. and O. Akinneye, 2004. Biological activity of tree marigold, Tithonia diversifolia, on cowpea seed bruchid, callosbruchus maculatus (Coleoptera: Bruchidea). Ann. Applied Biol., 144: 185-189. 
6. Edde, P.A., 2012. A review of the biology and control of Rhyzopertha dominica (F.) the lesser grain borer. J. Stored Prod. Res., 48: 1-18.

7. Jood, S., A.C. Kapoor and R. Singh, 1995. Amino acid composition and chemical evaluation of protein quality of cereals as affected by insect infestation. Plant Foods Hum. Nutr., 48: 159-167.

8. Edde, P.A., 2012. A review of the biology and control of Rhyzopertha dominica (F.) the lesser grain borer. J. Stored Prod. Res., 48: 1-18.

9. Mahroof, R.M., P.A. Edde, B. Robertson, J.A. Puckette and T.W. Phillips, 2010. Dispersal of Rhyzopertha dominica (Coleoptera: Bostrichidae) in different habitats. Environ. Entomol., 39: 930-938.

10. Jian, F., 2019. Influences of stored product insect movements on integrated pest management decisions. Insects, Vol. 10. 10.3390/insects 10040100

11. Jood, S., A.C. Kapoor and R. Singh, 1996. Effect of insect infestation and storage on lipids of cereal grains. J. Agric. Food Chem., 44: 1502-1506.

12. Ndakidemi, B., K. Mtei and P.A. Ndakidemi, 2016. Impacts of synthetic and botanical pesticides on beneficial insects. Agric. Sci., 7: 364-372.

13. Ileke, K.D. and M.O. Oni, 2011. Toxicity of some plant powders to maize weevil, Sitophilus zeamais (motschulsky) [Coleopteran:Curculiondae] on stored wheat grains ( Triticum aestivum). Afr. J. Agric. Res., 6: 3043-3048.

14. Udo, I.O., T.T. Epidi and J.A. Osakwe, 2011. Comparative efficacy of root, bark and leaf powders of Dracaena arborea for the control of two storage insect pests. Sci. Res. Essays, 6: 1473-1478.

15. Ileke, K.D. and O.F. Olotuah, 2012. Bioactivity of Anacardium occidentale (L.) and Allium sativum (L.) powders and oils extracts against cowpea bruchid, Callosobruchus maculates (Fab.) [Coleoptera: Chrysomelidae]. Int. J. Biol., 4: 96-103.

16. Ileke, K.D. and D.S. Bulus, 2012. Evaluation of contact toxicity and fumigant effect of some medicinal plant and pirimiphos methyl powders against cowpea bruchid, Callosobruchus maculates (Fab.) [Coleoptera: Chrysomelidae] in stored cowpea seeds. J. Agric. Sci., 4: 279-284.

17. Prakash, A., J. Rao, J. Berliner, S.S. Pokhare, T. Adak and K. Saikia, 2014. Botanical pesticides for the management of plant nematode and mite pests. In: Advances in Plant Biopesticides, Singh, D., Springer, India, pp: 89-118.

18. El-Wakeil, N.E., 2013. Botanical pesticides and their mode of action. Gesunde Pflanzen, 65: 125-149.

19. Athanassiou, C.G., P.U. Rani and N.G. Kavallieratos, 2014. The use of Plant Extracts for Stored Product Protection. In: Advances in Plant Biopesticides, Singh, D. (Ed.). Springer, New York, USA., ISBN: 9788132220060, pp: 131-147.
20. Boeke, S.J., I.R. Baumgart, J.J.A. van Loon, A. van Huis, M. Dicke and D.K. Kossou, 2004. Toxicity and repellence of African plants traditionally used for the protection of stored cowpea against Callosobruchus maculatus. J. Stored Prod. Res., 40: 423-438.

21. Tulukder, F.A. and P.E. Howse, 1994. Repellent, toxic and food protectant effects of pitraj (Aphanamixis polystachya) extracts against the palse beetle (Callosobruchus chinemis) in storage. J. Chem. Ecol., 20: 899-908.

22. Khater, H.F., 2012. Prospects of botanical biopesticides in insect pest management. Pharmacologia, 3: 641-656.

23. Dougoud, J., S. Toepfer, M. Bateman and W.H. Jenner, 2019. Efficacy of homemade botanical insecticides based on traditional knowledge. A review. Agron. Sustain. Dev., 39: 37-59.

24. Roman, P., 2016. History, presence and perspective of using plant extracts as commercial botanical insecticides and farm products for protection against insects - a review. Plant Protect. Sci., 52: 229-241.

25. Isman, M.B., 2006. Botanical insecticides, deterrents and repellents in modern agriculture and an increasingly regulated world. Annu. Rev. Entomol., 51:45-66.

26. Das, A.J., P. Khawas, T. Miyaji and S.C. Deka, 2015. Phytochemical constituents, attenuated total reflectance fourier transform infrared analysis and antimicrobial activity of four plant leaves used for preparing rice beer in Assam, India. Int. J. Food Prop., 19: 2087-2101.

27. Singh, D., A.K. Singh, 1991. Repellent and insecticidal properties of essential oils against housefly, Musca domestica L.. Int. J. Trop. Insect Sci., 12: 487-491.

28. Campos, E.V.R., P.L.F. Proença, J.L. Oliveira, M. Bakshi, P.C. Abhilash and L.F. Fraceto, 2018. Use of botanical insecticides for sustainable agriculture: Future perspectives. Ecol. Indic., 105: 483-495.

29. Kestenholz, C., C.P. Stevenson and S.R. Belmain, 2007. Comparative study of field and laboratory evaluations of the ethnobotanical Cassia sophera L. (Leguminosae) for bioactivity against the storage pests Callosobruchus maculatus (F.) (Coleoptera: Bruchidae) and Sitophilus oryzae (L.) (Coleoptera: Curculionidae). J. Stored Prod. Res., 43: 79-86.

30. Onoja, O.J., 2015. Efficacy of selected plant extracts against Tribolium castaneum Herbst in stored groundnut (Arachis hypogaea L.). Afr. J. Plant Sci., 9: 90-96.

31. Sarwar, M.I., M.N. Saleem, M.U. Gulzar, M.M. Shabbir and A. Ali, 2019. Effects of medicinal plants Moringa olifera, Calotropis procera, Citrullus colocynthis as toxicants against Tribolium castaneum. Nature Sci., 17: 71-76.

32. Dabire, C.L.B., F.B. Kini, M.N. Ba, R.A. Dabire and K. Fouabi, 2005. Effect of the stage of development of cowpea pods on the biology of the sucking bug Clavigralla tomentosicollis Stal. (Hemiptera: Coreidae). Int. J. Trop. Insect Sci., 25: 25-31. 
33. Dabire, C.L.B., M.N. Ba and A. Sanon, 2008. Effects of crushed fresh Cleome viscosa L. (Capparaceae) plants on the cowpea storage pest, Callosobruchus maculatus Fab. (Coleoptera: Bruchidae). Int. J. Pest Manage., 54: 319-326.

34. Odeyemi, O.O. and M.O. Ashamo, 2005. Efficacy of neem plant (Azadirachta indica) extracts in the control of Trogoderma granarium, a pest of stored groundnuts. J. Plant Dis. Prot., 112: 586-593.

35. Ogendo, J.O., S.R. Belmain, A.L. Deng and D.J. Walker, 2003. Comparison of toxic and repellent effects of Lantana camara L. with Tephrosia vogelii hook and a synthetic pesticide against Sitophilus zeamais Motschulsky (Coleoptera: Curculionidae) in stored maize grain. Int. J. Trop. Insect Sci., 23: 127-135.

36. Babarinde, S.A., O.O.R. Pitan and A.T. Ogunfiade, 2011. Bioactivity of Piper guineense Schum. and Thonn seed and Moringa oleifera Lam. leaf powder against Trogoderma granarium Everts (Coleoptera: Dermestidae). Arch. Phytopathol. Plant Prot., 44: 298-306.

37. Odewole, A.F., F.O. Alao, A.A. Agboola and B.F. Adedapo, 2014. Comparative efficacy of plant extracts with synthetic against insect pests of okra (Abelmoschus esculentus $\mathrm{L}$. Monech). Int. Letters Nat. Sci., 19: 52-58.

38. Koona, P. and S. Dorn, 2005. Extracts from Tephrosia vogelii for the protection of stored legume seeds against damage by three bruchid species. Ann. Applied Biol., 147: 43-48.

39. Belmain, S.R., B.A. Amoah, S.P. Nyirenda, J.F. Kamanula and P.C.Stevenson, 2012. Highly variable insect control efficacy of Tephrosia vogelii chemotypes. J. Agric. Food Chem., 60: 10055-10063.

40. Odewole, A.F., F.O. Alao, A.A. Agboola and B.F. Adedapo, 2014. Comparative efficacy of plant extracts with synthetic against insect pests of okra (Abelmoschus esculentus L. Monech). Int. Letters Nat. Sci., 19: 52-58.

41. Oumarou, M.K., L. Younoussa and E.N. Nukenine, 2018. Toxic effect of Chenopodium ambrosoides, Hyptis suaveolens and Lippia adoensis leaf methanol extracts and essential oils against fourth instar larvae of Anopheles gambiae (Diptera: Culicidae). Int. J. Mosq. Res., 5: 61-66.

42. Ileke, K.D. and A.T. Emmanuel, 2018. Bioefficacy of Alstonia boonei leaf extract against cowpea beetle Callosobrochus maculates infesting stored cowpea seeds in storage. Braz. J. Biol. Sci., 5: 673-681.
43. Emeasor, K.C. and P.N.Ndumele, 2019. Comparative toxicity of aqueous extract of Tephrosia vogelii and some synthetic insecticides in the control of insect pests of cucumber (Cucumis sativus L.). Greener Trends Plant Pathol. Entomol., 2: $1-8$.

44. Mbaiguinam, M., N. Maoura, A. Bianpambe, G. Bono and E. Alladoumbaye, 2006. Effects of six common plant seed oils on survival, eggs lying and development of the cowpea weevil, Callosobruchus maculatus(F.) (Coleoptera:Bruchidae). J. Boil. Sci., 6: 420-425.

45. Oigiangbe, O.N., I.B. Igbinosa and M. Tamo, 2007. Insecticidal activity of the medicinal plant, Alstonia boonei De Wild, against Sesamia calamistis Hampson. J. Zhejiang Univ. Sci. B, 8: 752-755.

46. Meena, B.L., K.L. Jeengar, B. Singh and N.L. Meena, 2016. Evaluation of different plant powders as seed protectants against rice moth, Corcyra cephalonica stainton. J. Appl. Nat. Sci., 8: 910-918.

47. Akhtar, Y. and M.B. Isman, 2004. Comparative growth inhibitory and antifeedant effects of plant extracts and pure allelochemicals on four phytophagous insect species. J. Applied Entomol., 128: 32-38.

48. Hikal, W.M., R.S. Baeshen and H.A.H. Said-Al Ahl, 2017. Botanical insecticide as simple extractives for pest control. Cogent Biol., Vol. 3. 10.1080/23312025.2017.1404274

49. Suleiman, M., C.P. Rugumamu and N.D. Ibrahim, 2018. Use of botanicals to suppress the development of maize weevil, Sitophilus zeamais Motsch. (Coleoptera: Curculionidae) in stored sorghum grains. J. Agric. Vet. Sci., 11: 1-10.

50. Abdullahi, N., A. Kabir and M. Yushau, 2011. Studies on the efficacy of lime peel oil in protecting stored maize against adult maize weevils (Sitophilus zeamais: Motschulsky). J. Entomol., 8: 398-403.

51. Salisu, N. and N.H. Ehimemen, 2020. Bio-efficacy of some plants ethanolic extracts against cowpea weevil (Callosobruchus maculatus fabricius) infestation of stored cowpea seeds. Asian J. Biotechnol., 12: 16-21.

52. Utono, I.M. and G. Gibson, 2015. New 'stimuli-enriched' laboratory bioassay used to identify improved botanical repellent treatment, Lem-ocimum, to control the stored-grain pest Tribolium castaneum. J. Stored Prod. Res., 64: 27-35. 